\title{
Miniaturized Multiplex Electrochemical Biosensor in Clinical Bioanalysis Pranjal Chandra*
}

Biomimetic Research Laboratory, Amity Institute of Biotechnology, Amity University Uttar Pradesh, Noida, India

Detection of a target molecule in environmental or clinical samples is extremely important and critical. There are ample of methods to diagnose or detect target molecule in various clinical samples. Methods based on genomic [1] and proteomic [2] assays using molecular methods are quite common and widely applicable all around the world. In clinical sample analysis usually either a protein biomarker [3, 4] (eg: human epidermal growth factor receptor 2 for breast cancer, prostate specific membrane antigen for prostate cancer) or a genetic biomarker [5] (eg: bone morphogenetic protein 3 gene for biliary cancer) is used to diagnose the occurrence or progression of a disease. Although a single biomarker can be used to diagnose a disease, but there are issues where a single biomarker alone cannot accurately predict occurrence of the disease [6]. To address this multi analyte detection various molecular methods have been developed such as; multiplex polymerase chain reaction analysis [7], multiplex ligation-dependent probe amplification [8], DNA microarray for gene expression or SNP detection assays [9], protein microarray [10], phage display [11] etc. These methods, however, are extremely powerful for multianalyte detection but they suffer due to their cost and inability of miniaturization for the onsite analysis. Furthermore, these methods require well qualified professionals for their real implementation in hospitals. Thus, in recent years a biosensor based multianayle detection of important clinical molecules have been attempted [12]. A biosensor is an analytical device used for the detection of a target molecule. It is composed of majorly two elements; a biological recognition element able to interact specifically with a target and a transducer able to convert the recognition event into a measurable signal [13]. Among the entire biosensor read out devices an electrochemical system method is usually preferred due to the advantages of being portable, simple, easy to use, cost-effective, disposable, and possible method for the lab-on-a-chip diagnostic system $[14,15]$. The multiplex biosensors that are capable of detecting multiple targets has provided more accurate diagnosis and monitoring in recent times. This type of biosensor technology relies on multiple transducers that are independently targeted to a specific protein or antigen for detection. Since this technology is reliable, low cost, and simply scaled-down with the use of semiconductor materials, electrochemical-based biosensors have been key players in the area of multiplex biosensors [16-18]. The performance of the electrochemical biosensor has been shown for nucleic acid [19] and protein biomarker [20] detection. Apart from the biosensor based systems, microfluidic device integrated with either an external [21] or an integrated biosensor [22] have been very well implemented in the simultaneous detection of various clinically important target molecules such as; anticancer drugs [21], sulfonamides [23], endocrine disruptors [24], and heavy metal ions [22]. In this regard, Chandra et al. developed a simple and highly sensitive method for the multiplex detection of anticancer drugs in urine samples using an amperometric biosensor composed of double stranded DNA and cardiolipin coupled with a microfluidic device [21]. The detection limit of these drugs was in $\mathrm{pM}$ range and the developed method detected these drugs simultaneously without any interference. Since DNA molecule is an extremely important molecule to diagnose a medical disorder, electrochemical multiplex biosensor has been attempted by many workers for various biomarkers. For instance; a novel electrochemical DNA biosensor for detection of a pre-core mutation in the hepatitis B virus was developed by oligonucleotide attached onto a nonfouling surface. The developed multiplexing method was able to analyze 16-samples simultaneously [25]. In an another study of multiplex DNA detection, very recently a hairpin DNA probe mediated cascade signal amplification technique has been developed for the quick DNA detection with a detection limit of $100 \mathrm{aM}$ [26]. The implementation of tag/anti-tag DNA and gold nanoparticles (NP's) reporters in this method allows a universal platform for the multiplex DNA detection without instrumentation. Apart of DNA molecules, proteins have also been detected by multiplex biosensor systems. In one example; an electrochemical immunosensor for detection of tumor markers has been developed. The biosensor consisted of an array of immunosensing electrodes fabricated on a glass substrate where each electrode was coated with a separate antigen and was able to make immuncomplex with a specific tumor marker [27]. This multiplexing biosensor was used to measure the concentrations of important tumor markers such as;alpha-fetoprotein, ferritin, carcinoembryonic antigen, human chorionic gonadotropin, CA 15-3, CA 125, and CA 19-9 with the detection limit of $<2 \mathrm{ng} / \mathrm{mL}$. In another study, a multiplexed biosensor using rapid and label free electrochemical impedance spectroscopy tuning method has been developed for the detection of inflammatory markers. An off-chip conjugation of gold NP's to the molecular recognition elements has been very well explored in this case [28]. In a very recent study, a microfluidic paperbased electrochemical biosensor array $(1 \times 8)$ has been developed as a diagnostic test of multiple biomarkers in a multiplexing approach [29]. In this case a paper-based device and the potentiostat formed a convenient, integrated, easy-to-operate electrochemical biosensing platform, which is mainly useful for low-cost, point-of-care diagnostic applications. Three important metabolic biomarkers (glucose, lactate and uric acid) were analyzed simultaneously which shows lower or comparable detection values to the detection system present in the market indication the potential application of multiplexing. These examples clearly illustrates that a multiplex biosensor assays provide significant advantages over single-analyte tests in terms of cost per test, labor, miniaturized diagnostic, handling large sample number, and convenience. It is possible to anticipate that miniaturized biosensor such as; paper based multianalyte system described herein, could be extremely appropriate for the mass manufacturing which will be surely economical and can be applied in a wide range of clinical samples.

In conclusion, the miniaturized multiplexing biosensor have

*Corresponding author: Pranjal Chandra, Biomimetic Research Laboratory, Amity Institute of Biotechnology, Amity University Uttar Pradesh, Noida, India, Tel: +91-120-4392644; E-mail: pchandral@amity.edu

Received November 29, 2013; Accepted November 29, 2013; Published December 07, 2013

Citation: Chandra P (2013) Miniaturized Multiplex Electrochemical Biosensor in Clinical Bioanalysis. J Bioanal Biomed 5: e122. doi:10.4172/1948-593X.1000e122

Copyright: (c) 2013 Chandra P. This is an open-access article distributed under the terms of the Creative Commons Attribution License, which permits unrestricted use, distribution, and reproduction in any medium, provided the original author and source are credited. 
Citation: Chandra P (2013) Miniaturized Multiplex Electrochemical Biosensor in Clinical Bioanalysis. J Bioanal Biomed 5: e122. doi:10.4172/1948$593 \mathrm{X} .1000 \mathrm{e} 122$

reached long way and will continue to move forward quickly in the next decade, with involvement of large number of companies into research and development. The principle platform and concern will be one offering high-throughput, rapid, and low cost diagnostics.

\section{Acknowledgement}

Pranjal Chandra thanks Amity University Uttar Pradesh, Noida, India for providing the research facility.

\section{References}

1. Kallioniemi A, Kallioniemi OP, Piper J, Tanner M, Stokke T, et al. (1994) Detection and mapping of amplified DNA sequences in breast cancer by comparative genomic hybridization. Proc Natl Acad Sci U S A 91: 2156-2160.

2. Wulfkuhle JD, Liotta LA, Petricoin EF (2003) Proteomic applications for the early detection of cancer. Nat Rev Cancer 3: 267-275.

3. Zhu Y, Chandra P, Song KM, Ban C, Shim YB (2012) Label-free detection of kanamycin based on the aptamer-functionalized conducting polymer/gold nanocomposite. Biosens Bioelectron 36: 29-34.

4. Min K, Song KM, Cho M, Chun YS, Shim YB, et al. (2010) Simultaneous electrochemical detection of both PSMA (+) and PSMA (-) prostate cancer cells using an RNA/peptide dual-aptamer probe. Chem Commun (Camb) 46: 55665568.

5. Kisiel JB, Li J, Zou H, Oseini AM, Strauss BB, et al. (2013) Methylated Bone Morphogenetic Protein 3 (BMP3) Gene: Evaluation of Tumor Suppressor Function and Biomarker Potential in Biliary Cancer. J Mol Biomark Diagn 4:145.

6. Morris VA (2013) Identification and prognostic significance of novel IRF8 transcripts in AML. Science Spotlight.

7. Elnifro EM, Ashshi AM, Cooper RJ, Klapper PE (2000) Multiplex PCR: optimization and application in diagnostic virology. Clin Microbiol Rev 13: 559570

8. Sorensen KM, El- SM, Fernlund E, Errami A, Bouvagnet P, et al. (2012) Screening of congenital heart disease patients using multiplex ligationdependent probe amplification: early diagnosis of syndromic patients. Am J Med Genet A 4: 720-725.

9. Yoo SM, Choi JH, Lee SY, Yoo NC (2009) Applications of DNA microarray in disease diagnostics. J Microbiol Biotechnol 19: 635-646.

10. Hanash S (2003) Disease proteomics. Nature 422: 226-232.

11. Deutscher SL (2010) Phage display in molecular imaging and diagnosis of cancer. Chem Rev 110: 3196-3211.

12. Wei F, Patel P, Liao W, Chaudhry K, Zhang L, et al. (2009) Electrochemical sensor for multiplex biomarkers detection. Clin Cancer Res 15: 4446-4452.

13. Chandra P, Noh HB, Shim YB (2013) Cancer cell detection based on the interaction between an anticancer drug and cell membrane components. Chem Commun (Camb) 49: 1900-1902.
14. Chandra P, Koh WC, Noh HB, Shim YB (2012) In vitro monitoring of i-NOS concentrations with an immunosensor: the inhibitory effect of endocrine disruptors on i-NOS release. Biosens Bioelectron 32: 278-282.

15. Noh HB, Chandra P, Moon JO, Shim YB (2012) In vivo detection of glutathione disulfide and oxidative stress monitoring using a biosensor. Biomaterials 33 2600-2607.

16. Xiao Y, Qu X, Plaxco KW, Heeger AJ (2007) Label-free electrochemical detection of DNA in blood serum via target-induced resolution of an electrodebound DNA pseudoknot. J Am Chem Soc 129: 11896-11897.

17. Liao JC, Mastali M, Gau V, Suchard MA, Møller AK, et al. (2006) Use of electrochemical DNA biosensors for rapid molecular identification of uropathogens in clinical urine specimens. J Clin Microbiol 44: 561-570.

18. Gau JJ, Lan EH, Dunn B, Ho CM, Woo JC (2001) A MEMS based amperometric detector for $\mathrm{E}$. coli bacteria using self-assembled monolayers. Biosens Bioelectron 16: 745-755.

19. Wei F, Wang J, Liao W, Zimmermann BG, Wong DT, et al. (2008) Electrochemical detection of low-copy number salivary RNA based on specific signal amplification with a hairpin probe. Nucleic Acids Res 36: e65.

20. Zhu Y, Chandra P, Shim YB (2013) Ultrasensitive and selective electrochemical diagnosis of breast cancer based on a hydrazine-Au nanoparticle-aptamer bioconjugate. Anal Chem 85: 1058-1064.

21. Chandra P, Zaidi SA, Noh HB, Shim YB (2011) Separation and simultaneous detection of anticancer drugs in a microfluidic device with an amperometric biosensor. Biosens Bioelectron 28: 326-332.

22. Noh HB, Chandra P, Kim YJ, Shim YB (2012) A simple separation method with a microfluidic channel based on alternating current potential modulation. Anal Chem 84: 9738-9744.

23. Won SY, Chandra P, Hee TS, Shim YB (2013) Simultaneous detection of antibacterial sulfonamides in a microfluidic device with amperometry. Biosens Bioelectron 39: 204-209.

24. Noh HB, Lee KS, Lim BS, Kim SJ, Shim YB (2010) Total analysis of endocrine disruptors in a microchip with gold nanoparticles. Electrophoresis 31: 30533060.

25. Liu G, Lao R, Xu L, Xu Q, Li L, et al. (2013) Single-nucleotide polymorphism genotyping using a novel multiplexed electrochemical biosensor with nonfouling surface. Biosens Bioelectron 42: 516-521.

26. Liu J, Chen L, Lie P, Dun B, Zeng L (2013) A universal biosensor for multiplex DNA detection based on hairpin probe assisted cascade signal amplification. Chem Commun (Camb) 49: 5165-5167.

27. Wilson MS, Nie W (2006) Multiplex measurement of seven tumor markers using an electrochemical protein chip. Anal Chem 78: 6476-6483.

28. La Belle JT, Fairchild A, Demirok UK, Verma A (2013) Method for fabrication and verification of conjugated nanoparticle-antibody tuning elements for multiplexed electrochemical biosensors. Methods 61: 39-51.

29. Chen Z, Martin MT, Xinyu L (2013) A microfluidic paper-based electrochemical biosensor array for multiplexed detection of metabolic biomarkers. Sci Techno Adv Mater 14: 054402. 